\title{
Entre Oswald e Oficina: as cinco faces do Mangue
}

\author{
Luciana Ferreira ${ }^{\mathrm{i}}$
}

\section{RESUMO}

O presente artigo busca tecer algumas reflexões sobre o percurso criativo feito pela Associação de Teat(r)o Oficina Uzyna Unona para construir cenicamente a zona de prostituição como espaço de diversas formas de opressão e dominação a partir da obra literária "O Santeiro do Mangue: mistério gozoso em forma de ópera", de Oswald de Andrade. Para esta investigação, procuramos também diferentes fontes de representação do Mangue em obras de artes visuais (em especial do período modernista) para relacionar a pluralidade de olhares e posicionamentos sobre o tema com o texto literário e sua apresentação no teatro, procurando abordar as interfaces entre literatura, teatro e artes plásticas.

Palavras-chave: Oswald de Andrade; Oficina; Mangue; Artes Visuais; Teatro.

\begin{abstract}
This article seeks to think about the creative path taken by the Associação de Teat(r)o Oficina Uzyna Unona to show the prostitution zone as a space for various forms of oppression and domination based on the literary work "O Santeiro do Mangue: mistério gozoso em forma de ópera", by Oswald de Andrade. For this investigation we also look for different sources that represent the Mangue in works of visual arts (especially from the modernist period) to relate the plurality of views and positions on the theme with the literary text and its presentation in the theater, seeking to address the interfaces between literature, theater and plastic arts.
\end{abstract}

Keywords: Oswald de Andrade; Oficina; Mangue; Visual Arts; Theater.

\section{INTRODUÇÃO: O MANGUE CHEGA AO PALCO}

\footnotetext{
i Possui Licenciatura em História da Arte pela Universidade do Estado do Rio de Janeiro (2005), cursando Especialização em Literatura Brasileira (ingresso em 2020) e Mestrado em Teoria da Literatura e Literatura Comparada (ingresso em 2021) junto ao Instituto de Letras da Universidade do Estado do Rio de Janeiro. ORCID: https://orcid.org/0000-0001-6396-7268. E-mail: luhbusson@gmail.com.
} 
Uma das obras menos conhecidas de Oswald de Andrade é "O Santeiro do Mangue”. A obra foi escrita entre 1935 e 1950 e teve diversas versões que ficaram sob os cuidados de Mário da Silva Britto e Mário Chamie. Exceto por uma versão mimeografada por Chamie, em 1967, o texto só pode ser conhecido graças a Renato Cordeiro Gomes (1985), cuja dissertação de mestrado, "Plural de Vozes na Festa (?) do Mangue", trouxe três versões do texto como anexo. Em 1991 a editora Globo publicou "O Santeiro do Mangue" em livro e, no carnaval de 1994, o Teat(r)o Oficina Uzyna Uzona, sob a direção de José Celso Martinez Corrêa, fez a primeira montagem teatral da peça para o grande público, com o título "Mistérios Gozozos".

"O Santeiro do Mangue: mistério gozoso em forma de ópera” é um poema dramático que denuncia, de forma contundente, as condições de vida das mulheres que vivem na zona de baixo meretrício do Rio de Janeiro, conhecida como Mangue, através da história de amor entre Seu Olavo, que vende imagens de santos, e a prostituta Eduléia. De acordo com Jorge Schwartz (2013), “O Santeiro do Mangue” tem como características marcantes a violência, o sarcasmo e a transgressão. Ainda segundo Schwartz:

Oswald de Andrade escolhe o Mangue como um ponto de confluência de relações humanas degradadas, cercado por um espaço urbano, cenário de subversões em que se mesclam o sagrado com o profano, e radicalizam os vínculos entre o dominador e o dominado (SCHWARTZ, 2013, p. 93).

Ao escrever sobre a vida das mulheres prostituídas na primeira metade do século XX do Rio de Janeiro, Oswald de Andrade denuncia as condições de vida do lugar, um "esgoto sexual da burguesia", cuja existência se perpetua graças à miséria daquelas que dependem da prostituição para viver e à hipocrisia das classes dominantes que não hesitam em buscar no Mangue a satisfação de seus desejos torpes sem se importarem com as condições de vida das mulheres que viviam naquele local.

A Associação de Teat(r)o Oficina Uzyna Uzona realizou duas temporadas de "Mistérios Gozozos", nos anos de 1994 e 2015. Há mais de cinco décadas, o grupo Oficina trabalha com textos de Oswald de Andrade, fazendo com que sua obra chegue ao palco com a força, originalidade, humor e crítica pretendidos pelo autor. Foi devido à montagem teatral de "O Rei da Vela", em 1967, que Oswald passou a ser relido e redescoberto no país. Assim, podemos dizer que o coletivo Oficina construiu, através de 
sua história, o senso de responsabilidade na mediação entre a obra de Oswald de Andrade e o público leitor.

No ano de 2012, José Celso utilizou o seu blog para se posicionar contra a forma como "O Santeiro do Mangue" foi publicado pela editora Globo. De acordo com o diretor, a versão escolhida teria desconsiderado as diferentes versões da obra e teria dado ao texto um tom panfletário que não fazia parte da intenção original de Oswald de Andrade. Com intuito de facilitar o acesso do público a outras interpretações do poema de Oswald, José Celso publica "Mistérios Gozozos", texto teatral do Oficina, "inspirado no trabalho acadêmico de Renato Cordeiro Gomes [...] que nos fez chegar a uma versão final da peça, depois de estudar sua pesquisa" (CORRÊA, 2012, s/p).

A proposta deste trabalho é analisar as estratégias utilizadas na montagem de "Mistérios Gozozos" (2015) para levar ao palco as questões sociais apontadas no texto literário "O Santeiro Do Mangue", articulando ambos com as diferentes abordagens do tema da prostituição nas artes plásticas da época em que o poema foi escrito.

No poema o personagem Estudante Marxista declara: “O que existe é a classe. O indivíduo não existe" (ANDRADE, 1991, p.38). Esta fala deixa clara a proposta do autor em focalizar os problemas sociais ao invés de conflitos individuais. Assim, no Mangue oswaldiano, temos a construção da polifonia da obra através das vozes de personagens que representam diferentes classes sociais e que travam seus embates em sua convivência naquele espaço: Eduléia, Jesus das Comidas, Seu Olavo, o Estudante Marxista, o Marinheiro, o Homem das Ferramentas, Satã, o Comissário de Polícia. Grande parte da voz das mulheres é condensada na personagem principal, Eduléia. As demais falas femininas significativas são reservadas ao coro de mulheres.

A montagem teatral preserva a luta de classes do poema, mas opta por mostrar mais detidamente os diversos problemas que afetam as mulheres do Mangue, ampliando a polifonia do texto escrito ao criar mais personagens pertencentes à classe das prostitutas que falam, cantam e atuam durante o espetáculo, mostrando que há diferenças na forma como a situação de vida em comum afeta cada uma delas. Isso possibilita ao teatro mostrar mais detidamente algumas faces da opressão que no texto literário são referenciadas ou apontadas rapidamente, na síntese contundente característica de Oswald de Andrade. 
Este recurso possibilita ao teatro demonstrar os diversos tipos de opressão, dominação e exploração no Mangue, que irão afetar mulheres diferentes em maior ou menor grau. Todos eles concorrem para reforçar o mecanismo de exclusão e discriminação maior, da prostituição, que mantém todas elas assujeitadas. Ou seja, o teatro Oficina, desenvolvendo a ideia do Mangue-prostíbulo como zona de exclusão de Oswald, coloca em evidência algumas faces específicas deste, que se correlacionam com a prostituição e interferem diretamente na vida das mulheres. É interessante notar que são condições associadas tradicionalmente a camadas mais pobres da sociedade e, devido a isso, são vistas como inferiores (ou inferiorizantes) pelas classes dominantes.

É importante lembrar também que para construir a peça de teatro, o grupo Oficina utilizou, além das três versões de "O Santeiro do Mangue", o trabalho de análise da obra de Renato Cordeiro Gomes (1985) e diversas obras de arte cuja temática é a prostituição no Mangue no Rio de Janeiro das décadas de 1930, 1940 e 1950, contemporâneas a Oswald. A preocupação de diversos artistas em representar o Mangue foi debatida por Jorge Schwartz no ensaio "Lasar Segall: um ponto de confluência de um itinerário afro-latino-americano" (2013), em que o autor mostra a presença do tema nas obras de Di Cavalcanti, Lasar Segall, Vinicius de Moraes, Manuel Bandeira, entre outros. Houve também uma exposição chamada "Poéticas do Mangue", em 2012, no Museu Lasar Segall, que reuniu trabalhos de diferentes artistas como: Cícero Dias, Hélio Oiticica, Poty Lazzarotto, Antonio Gomide, entre outros, com objetivo de mostrar a diversidade de perspectivas sobre o tema, conforme informa texto escrito por Fábio Magalhães, curador da exposição, no site do museu.

Passo agora a analisar os diálogos existentes entre texto literário, peça teatral e obras de arte na construção de diferentes aspectos do Mangue, compreendendo a zona de baixo meretrício como espaço de vivência/existência dos marginalizados.

\section{O MANGUE FEMININO}

Embora as mulheres não sejam as únicas a vender seus corpos, a face da prostituição é predominantemente feminina. À venda de favores sexuais, somam-se questões femininas que, embora guardem relações com a prostituição, estão presentes no cotidiano de diversas mulheres, independente da profissão: violência doméstica (no 
poema, Olavo e Eduléia se agridem fisicamente, no palco ele aponta uma arma para cabeça dela); ciúmes e incompreensão do parceiro (tanto no poema quanto no teatro, Olavo sofre por não poder ter Eduléia apenas para si e fica violento diante da possibilidade de ela ter sentido prazer com outros homens); abandono do companheiro (Eduléia, no início da história, namora com Navá, um marinheiro que está ausente e que só retorna após sua morte, outras mulheres no palco reclamam da ausência de seus amantes); carência afetiva e solidão ("Só me resta a cachaça e o amô / Faço apenas pra minha refeição / Não tenho ninguém na minha história”, canta uma das prostitutas no palco); infidelidade do parceiro (seu Olavo acha natural procurar outra mulher porque sua esposa está grávida); perda de dignidade por ter feito sexo antes do casamento (Eduléia é condenada ao mangue por ter se deixado seduzir pelo Homem da Ferramenta); objetificação (“do you do sacanagem com uma brasileira?”, pergunta o guia aos turistas ou "vão todos ver se ela é boa dos bicos", diz Jesus das Comidas sobre Deolinda); exploração financeira (Olavo tira todo o dinheiro que Eduléia ganha com a prostituição); desespero diante da impossibilidade de garantir a alimentação dos filhos (Deolinda vai ao Mangue porque sua filha tem fome); temor diante da possibilidade que suas filhas precisem ter o mesmo destino que as mães ("Um filho vai nascê / Olavo se for home / Se for muié / Que nome porá?”, pergunta o coro. A resposta de Deolinda é veemente: "Nome de puta não!"); suicídio (Eduléia toma veneno por não conseguir dinheiro suficiente).

Além disso, há uma total indiferença e falta de solidariedade por parte dos personagens masculinos diante dos problemas das mulheres, ainda que eles sofram com as mesmas condições de pobreza: Jesus das Comidas não se comove diante da fome nem diante do iminente suicídio de Eduléia; Olavo não se importa diante do desejo expresso pela amante de sair do Mangue e não mostra nenhuma inquietação por ver seu filho com Deolinda passando fome; o Estudante Marxista tenta instilar nas mulheres a consciência de classe e a revolta com as condições de vida para convencê-las a lutarem pelos objetivos que ele considera importantes; a polícia é sistematicamente violenta com as prostitutas; o Navá se vinga de Olavo, mas não demonstra pesar pela morte da namorada. Podemos ver o jogo de forças entre homens e mulheres expresso em imagens como a gravura Casal no Mangue, de 1943 (Disponível em: https://www.moma.org/collection/works/19511), de Lasar Segall, em que vemos um 
homem totalmente vestido, com a boca aberta, em atitude de posse, tomando o corpo de uma mulher nua. $\mathrm{O}$ rosto dela demonstra claramente seu desinteresse e desgosto com a situação. Há um contraste bem grande com a volúpia colorida mostrada por Di Cavalcanti em Mangue, de 1929 (Disponível em: https://enciclopedia.itaucultural.org.br/obra2610/mangue). Se observarmos as duas imagens lado a lado, podemos compreender os comportamentos opostos das mulheres do mangue no palco: quando não há homens por perto, elas lamentam, praguejam, xingam, rezam. Já quando há clientes presentes, elas cantam e dançam, sorrindo sensualmente.

\section{O MANGUE NEGRO}

Embora as personagens principais sejam brancas e não se faça um debate explícito ou profundo sobre o racismo, a presença de uma maioria de mulheres negras em uma zona de prostituição pobre já é apontado no poema de Oswald: "É o navio humano quente / Negreiro do Mangue" (ANDRADE, 1991, p. 35). O teatro traz atrizes negras e coloca a presença de elementos da cultura negra no palco como contraponto com a cultura branca, católica e burguesa da classe dominante. Podemos ver isso através das músicas (cabe lembrar que Mistérios Gozozos é um musical): a banda faz amplo uso de instrumentos musicais africanos como cuíca, berimbau, afoxé, atabaque, entre outros. Parte da trilha evoca pontos de umbanda. As canções que não são cantadas pelo coro são majoritariamente vocalizadas por atrizes negras (com destaque para Célia Assunção e Denise Nascimento), valorizando a unicidade vocal de cada uma delas: a voz de Célia é doce e suave, traz o jeito de cantar do samba de raiz, enquanto a potência vocal de Denise remete às performances das cantoras de jazz.

Há, ainda, a forte presença de elementos de religiões afro-brasileiras - umbanda e candomblé - no cotidiano do mangue, que serão abordadas mais detidamente na parte dedicada à religião.

Ao pensarmos na questão da negritude no Mangue, não há como ignorar o artista plástico do modernismo que mais se preocupou em mostrar como a pobreza e a prostituição afetavam particularmente as mulheres negras: Segall. De acordo com Jorge Schwartz, Segall se dedicou durante três décadas a representar o Mangue e a temática 
negra. $\mathrm{O}$ autor vê nas persianas, constantes no mangue segalliano, uma referência à segregação e à prisão a que as mulheres negras estariam submetidas. Algumas imagens onde podemos ver estes elementos são Cabeça atrás da Persiana, de 1929 (Disponível em: $\quad$ https://artsandculture.google.com/asset/cabe\%C3\%A7a-atras-da-persiana/QEzBWEuK1klTQ?hl=pt-BR) e Casa do Mangue, de 1929 (Disponível em: http://enciclopedia.itaucultural.org.br/obra34480/casa-do-mangue). Para Schwartz:

\begin{abstract}
As prostitutas de Segall identificam a condição da negritude, somada à condição social da pobreza. [...] o espaço da pobreza, da solidão e a total ausência de identidade individual negam qualquer possibilidade de erotização dessa paisagem humana descarnada. Sem dúvida, Segall tinha todos os elementos para dar-lhe uma interpretação erótica [...] mas escolheu, ao contrário, o páthos e o tom da tragédia, reconhecível já em sua obra expressionista e na temática judaica (SCHWARTZ, 2013, p. 85).
\end{abstract}

Neste texto o autor também chama a atenção para a confluência entre os Mangues de Oswald e Segall no tocante à crítica social, destacando que a poesia traz uma carga maior de denúncia virulenta, enquanto as gravuras são mais eficazes ao evocar a melancolia e o aspecto do trágico naquelas vidas. Ambas, cada uma a seu modo, mostram a precariedade da situação.

\title{
O MANGUE RELIGIOSO
}

Conforme indica Renato Cordeiro Gomes (1985), Oswald de Andrade constrói o Mangue a partir da oposição entre sociocentrismo e teocentrismo, em que a religião católica tem como objetivo principal manter a ordem e alienar as pessoas.

As prostitutas, ameaçadas pelo fantasma da fome, por doenças e pela degradação cotidiana, rezam para figuras religiosas que são insensíveis ao seu sofrimento. Oswald de Andrade indica essa hipocrisia desde a dedicatória de seu texto: as diferentes versões incluem senhoras católicas; os poetas Murilo Mendes e Jorge de Lima, que faziam poemas com temática católica; o pintor Ismael Nery, também notoriamente católico; o Exército da Salvação; os michês. Gomes chama a atenção ao fato de que essas dedicatórias constituem um elemento textual: o poeta utiliza esse recurso para mostrar a inutilidade de um mundo sobrenatural frente a um cotidiano extremamente difícil, 
fazendo do catolicismo uma das principais forças responsáveis pela manutenção da zona e da ordem estabelecida.

No palco Jesus das Comidas fica na maior parte do tempo acima de todos, evidenciando seu distanciamento e atitude de superioridade. Trata-se de um personagem que frequenta o Mangue, mas quer se manter o mais afastado possível daquele lugar. Eventualmente desce para interagir com suas devotas, jamais com o intuito de amparar ou prestar o consolo que se espera de uma figura religiosa: ele condena uma Eduléia adolescente "a ganhar o pão com o suor das coxas", se deita com as prostitutas, coloca bananas em lugar de hóstias na boca das mulheres, instiga a revolta nos outros devido ao sentimento de amor que Olavo confessa, dá de ombros diante do suicídio iminente de Eduléia, urina sobre o Mangue. Em um único momento tenta defender a permanência das mulheres na zona contra aqueles que pedem o fim daquele espaço, sob a seguinte justificativa: "elas são necessárias". Com suas atitudes, deixa claro que é um santo da burguesia, trabalhando a favor da manutenção de um gueto que sirva para manter os interesses da classe dominante, sem qualquer sentimento de remorso ou compaixão. Apesar disso, os desvalidos do Mangue - tanto as prostitutas quanto Olavo ou o Marinheiro - o tratam com deferência e continuam a esperar dele apenas coisas boas.

O personagem de Jesus das Comidas acaba, assim, sendo uma metáfora para representar os clientes da zona, figuras que de outro modo pouco aparecem no Mangue. As prostitutas esperam obter através dele seu sustento e alguma empatia, mas Jesus das Comidas (à semelhança dos homens, presume-se) escolhe explorar as mulheres, indiferente aos seus destinos e preocupado em mantê-las na situação de pobreza, dependência e subserviência para que o Mangue continue a ser útil. Afinal, conforme nos explica o Estudante Marxista: "Mas o que importa a uma sociedade organizada é possuir e manter o seu esgoto sexual. A fim de que permaneça pura a instituição do casamento. Para que não seja necessário o divórcio. E vigorar a monogamia e a herança. A burguesia precisa do Mangue" (ANDRADE, 1991, p. 38)

O coro das mulheres no palco deixa claro o entrelaçamento entre prostituição e religião católica (“Temos um escapulárío aqui / E duas troquesa lá”). Na peça de teatro, a narração cabe ao anjo Serafim. A descrição de Olavo, que vai ao Mangue vender os Santos, deixa clara a crença incondicional no poder sobrenatural dos santos. O Serafim o descreve para o público: "Seu Olavo / Tem dois metro / Cara feia / Olhera / Cara 
fodida / De pipoca / Mas carrega / Mancheias de milagres”. Todas as prostitutas possuem a imagem da Santa Ceia para que não lhes falte "o pau nosso de cada noite". Quando precisam de dinheiro, correm para rezar e pedir piedade a Jesus das Comidas.

A todos esses elementos que demonstram a hipocrisia e inutilidade do catolicismo, diversos elementos não textuais trabalham para trazer ao palco a presença de religiões afro-brasileiras, em especial a umbanda. O figurino de Eduléia, formado por saias vermelhas bem rodadas, evoca as vestes da Pomba Gira, entidade associada à proteção das prostitutas. Quando o Marinheiro vai vingar a morte de Eduléia, o coro feminino canta no ritmo dos pontos de Umbanda da Pomba Gira. Estas referências surgem no texto teatral, uma vez que o poema de Oswald de Andrade não menciona religiões de matriz africana. Uma interpretação possível para este acréscimo é a existência de outras religiões como forma de resistência diante da hegemonia do catolicismo. Não há interferência direta de nenhuma entidade ou divindade da umbanda na história, evidenciando a concordância do teatro com a visão expressa por Oswald sobre a inutilidade de qualquer credo religioso no Mangue.

Olavo vai ao Mangue porque é o único lugar onde ainda é possível vender imagens de santos em tamanho grande. É um santo o responsável pela aproximação do par romântico da história: Eduléia troca seus favores sexuais por um dos santos de Olavo e a imagem fica em seu quarto ao longo do desenrolar da trama. Dentre todas as imagens, é justamente São Jorge que chama atenção de Eduléia. Este santo católico é associado a Ogum na umbanda e no candomblé. As cores de Ogum na umbanda são as mesmas de São Jorge: vermelho e branco. Não é por acaso que são estas as cores presentes no figurino do Marinheiro "dono" de Eduléia. Nas cenas em que Eduléia está deitada em sua cama, podemos ver a imagem de São Jorge, evocando a presença ausente dos homens de sua vida: o santeiro, que lhe deu a imagem; o marinheiro, cujas roupas correspondem ao santo e, através do ato de adoração a uma figura divina, Jesus das Comidas. A montagem teatral deixa claro que não há um espaço possível para que Eduléia possa respirar, existir ou sonhar de forma independente dos homens que a cercam. Mesmo a ressurreição de Olavo e Eduléia mostra não o início de uma nova vida, mas um círculo vicioso: Olavo vira cafetão e presenteia sua amada com a imagem de um "santo" peculiar: um falo gigante, diante do qual ela se coloca em atitude religiosa, decerto rezando pelo "pau nosso de cada noite". 
O "Santeiro do Mangue" termina com o fim da zona e o poema chamado "Anda depressa, Timochenko", deixando clara a tomada de consciência política das pessoas como única saída possível para que a prostituição acabe: "Vem nos ajudar a sair destas senzalas / Atlânticas / Para que seja eterna a glória / Dos que tombaram em defesa da liberdade / E da pátria / De todos os trabalhadores do mundo / Vem / Estamos prestes a lutar / Prestes"(ANDRADE, 1991, p. 44). No teatro, devido ao tempo decorrido entre as duas obras e à grande diferença no panorama político do país e do mundo, seria muito difícil realizar o mesmo final. O grupo Oficina opta por não sugerir nenhuma solução óbvia e aponta o girar das engrenagens: Jesus das Comidas passa a ser o Santeiro e vende a seu Olavo a imagem que será o presente de Eduléia. Olavo, por sua vez, é aquele que coloca a mulher em atitude devota diante do falo. Fica evidente que, mesmo com o fim do Mangue e com a troca de papéis entre os homens, ambos continuarão a garantir sua existência através da exploração de Eduléia e que a única saída que ela tem diante de si é rezar para que as coisas sejam diferentes.

\section{O MANGUE POBRE}

A miséria e a sujeira são as marcas mais profundas do Mangue. Tudo que constitui a vida na zona é repulsivo, pobre, desprezível. Nem o mar tem permissão de ser belo ali. "O mar que mais parece um caramujo cor de chumbo / Plúmbeo..." (ANDRADE, 1991, p. 22). O coro repete, no início da peça: "tenho fome". A preocupação das mulheres é garantir o sustento. Por isso explicam, cantando, os motivos de sua fé: "E a Deus tememos / para que não nos falte / o pau nosso / de cada noite”. Não há possibilidade para qualquer critério de escolha dos parceiros de cama. Uma das prostitutas vocaliza a angústia de todas as mulheres que esperam clientes: "Não sei quem é que vai entrá / Michê, pesteado ou navá". Lasar Segall ilustra bem esta falta absoluta de opção das mulheres na xilogravura Casal no Mangue, de 1929 (Disponível em: https://artsandculture.google.com/asset/casal-do-mangue-lasarsegall/cQHKQfwc3acfbw?hl=pt-BR) em que mostra uma mulher de frente e o vulto de um homem de costas: vemos o rosto feminino, sua expressão facial, sua boca aberta, os olhos vazados. Diante dela - e de costas para nós - há a silhueta de um homem, totalmente coberto pelas sombras. É impossível distinguir qualquer traço físico. Quem é 
ele? É feio ou bonito? Jovem ou velho? Pobre ou rico? Qual é a cor da sua pele ou dos seus olhos? Estará alegre, bêbado, triste? Será gentil ou violento? Não podemos saber porque não importa, nem a nós nem a ela. A única coisa que importa é que ele se deite com aquela mulher e pague por isso, assim ela poderá garantir seu sustento naquela noite.

A consequência é um estado de vulnerabilidade extremo: além da fome, as mulheres se encontram cronicamente afligidas por doenças que se confundem com suas próprias identidades. Algumas carregam no nome a falta de saúde: Rosa Tuberculosa, Lulu Titica Sifilítica, Turca Maluca, Maroca Louca. Eduléia tem o "pequenino sexo calcinado por lavagens"(ANDRADE, 1991, p. 30). Isso deixa claro que apesar de as doenças afetarem tanto homens quanto mulheres, o estigma da doença cai apenas sobre elas. Mesmo às custas da própria saúde, as mulheres pedem pelas doenças - quase que desejam contraí-las, porque no Mangue ser contaminada pelas doenças é sinônimo de ter feito um programa e, consequentemente, de ganhar dinheiro e assegurar a sobrevivência. Assim podemos compreender falas emblemáticas como a de Deolinda: “Ó gonorreia! Ó gonorreia / Vem cá! / Ó cancro duro da vida / Eu te pertenço / Minha filha tem fome / Vem cá!"

Outro aspecto que aflige as mulheres da zona é o sustento e destino de suas filhas. Eduléia se suicida por não conseguir dinheiro suficiente para alimentar a filha de Olavo. Viúva e sem ter qualquer tipo de amparo, Deolinda acaba no Mangue para garantir o sustento de sua criança. Todos sabem para onde irão as meninas pobres: logo após Deolinda dar a luz a uma menina, o Serafim narrador pergunta: "Uma criança não tem defesa / Nasceu no morro / É Fêmea / O que é que ela vai ser?”. Um pouco mais adiante há o perturbador coro de vozes infantis que seguem cantando alegremente para o Mangue: "Ciranda Cirandinha / Vamos todos cirandar / Nosso Corpo vamos dar / Aos que podem nos pagar / Ciranda Cirandinha / Tudo que temos vamos dar / Nosso corpo nossa alma / Tudo, tudo vamos dar”. É impossível não recordar o quadro de Edvard Munch, pintor do expressionismo alemão (escola a que Segall também pertenceu), intitulado Puberdade, de 1894 (Disponível em: $\underline{\text { http://www.edvard- }}$ munch.org/puberty/). Embora o tema da pintura não seja o da prostituição, podemos ver uma menina muito jovem, nua, com o rosto sério, olhos arregalados, tentando esconder o corpo na transição entre infância e maturidade. A relação entre sexualidade, juventude 
e vulnerabilidade é evidente. Seu corpo pálido e magro se destaca do fundo, fazendo um contraste com a grande sombra negra da parede. De acordo com Argan (1992, p. 256), a sombra é uma referência ao futuro da menina e às difíceis condições de vida reservadas às mulheres na sociedade da época.

Somadas a todas essas agruras, há a consciência da exploração e abuso que sofrem constantemente por todos os lados e a sensação de impotência diante do fato ou, conforme canta a prostituta em seu solo: "A venda me exprora / O Tira me exprora / O Cafetão 171 me xinga / Meu home, meu home / qué mi dá nimim", canta uma das prostitutas. O cotidiano da zona acontece entre surras da polícia, curiosidade dos turistas que visitam a zona por estarem cansados da beleza da cidade, violência dos companheiros que deveriam amá-las, incapacidade de assegurar alguma dignidade a si mesmas e a suas crianças, absoluta ausência de saúde física e mental, subserviência a figuras religiosas, constante corrida pelo dinheiro.

\section{O MANGUE PROSTITUÍDO}

Tanto o texto literário quanto a peça de teatro são perspicazes ao mostrar que todas estas formas de opressão concorrem juntas para formar a "senzala atlântica" (ANDRADE, 1991, p. 44), que é a zona de meretrício. Há um mecanismo de exclusão particularmente eficaz para reforçar todos os outros e manter as mulheres presas àquele espaço: o estigma da prostituição. Apesar de ficar claro para o público a humanidade das personagens e as dificuldades constantes que enfrentam, em nenhum momento é permitido esquecer que aquelas mulheres são, antes de mais nada, prostitutas. Não nos é permitido olhar para suas existências de forma dissociada da venda de favores sexuais.

No texto vemos o trabalho para que todos os elementos associados ao feminino tenham uma apresentação de prostituta: "Noite hetaira / Engalanada / Enjaulada / No lodaçal”. A lua, da mesma forma, tem uma função específica: iluminar a rua e atrair os clientes ("Lá em cima / a lua cheia / Lá embaixo / a rua cheia”). Não há mulheres na representação do mangue que não sejam prostitutas ou prostituíveis: Deolinda, descrita no início da história como esposa virtuosa e cujo figurino é um manto azul como o de Nossa Senhora, acaba no quarto e na cama de Eduléia. Sabemos bem o destino das crianças. A única exceção é Madame Dilma Bovary no cassino. Cabe lembrar, no 
entanto, que não é um acaso a escolha de Oswald por Madame Bovary: trata-se de uma personagem literária com a sexualidade desviante do padrão de sua época e que termina se suicidando (com veneno, como Eduléia). Em diversos momentos podemos testemunhar diferentes personagens se dirigindo às mulheres como "putas", "vacas" ou "vagabundas". Em suas preces, as prostitutas rogam a Jesus que não se esqueça de ajudá-las porque ele mesmo "foi michê / da nossa colega / Madalena" (ANDRADE, 1991, p. 31).

O teatro reforça os elementos do texto: Eduléia passa grande parte da peça total ou parcialmente nua, deitada em sua cama, de pernas abertas, oferecendo o sexo a todos. Algumas músicas cantadas pelas mulheres possuem letras que associam amor e dinheiro (por exemplo: "Um beijo por minuto", de Gabriel Gava). Jesus das Comidas enfia o rosto entre as pernas de Deolinda sem trocar uma palavra com ela. A cama de Eduléia e Deolinda, no palco, tem uma reprodução da pintura $O$ Sonho da Prostituta, de 1930 (Disponível em: http://enciclopedia.itaucultural.org.br/obra2704/o-sonho-da-prostituta), de Cícero Dias: cercada de luzes em um quartinho, como uma santa em um oratório, só é possível ver seu corpo, o rosto não importa (é indiferente tratar-se de Deolinda, Eduléia ou qualquer outra). A evidência está no corpo, nas pernas abertas, na única coisa que vale a atenção e o dinheiro dos homens do Mangue.

O quadro é dividido verticalmente em duas partes: o confinamento do quarto da prostituta e a representação do sonho, com cores claras, uma paisagem aberta e ampla, com figuras oníricas, evocando a liberdade. Porém é interessante notar: o sonho da prostituta é também uma fila interminável de clientes brancos (sem cor, sem identidade ou profundidade), de papel. A fila de clientes é sem dúvida a parte menos trabalhada da pintura e o anonimato das figuras contrasta com a evidência dada à prostituta. É como se Cícero Dias invertesse os valores expressos na "Oração do Mangue" de Oswald. Agora são os homens que estão em romaria, são eles que suplicam pelos favores da mulher que se vende, mas, mesmo no mundo onírico, a prostituta não se permite sonhar sem depender do "pau nosso de cada dia”. Não há outra existência possível para a prostituta, quaisquer que sejam os mundos em que ela habite.

Em "Mistérios Gozozos", a canção que melhor sintetiza o que significa a prostituição pobre e suas consequências deletérias é Flores Horizontais. A música é executada logo após Jesus das Comidas urinar sobre o Mangue, encerrando a existência 
do lugar e deixando as prostitutas sem terem para onde ir. Aqui podemos sentir e ouvir o lamento das criaturas que acabam de perder tudo, até mesmo a lama onde se afundavam e graças a qual podiam sobreviver:

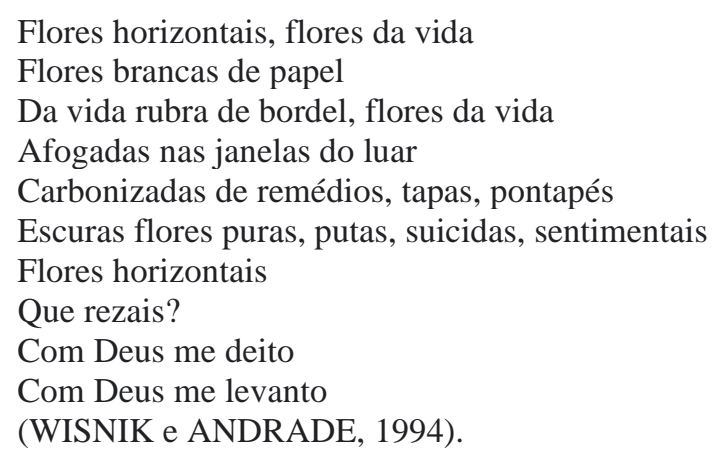

Para montar a letra, José Wisnik recorre ao recorte e rearranjo de versos do poema Oração do Mangue, que integra "O Santeiro". Nesse processo de escritura antropófago, que se apropria dos versos para transformá-los em seus, Wisnik evoca dois procedimentos de vanguarda da arte moderna do século XX: o ready-made, por partir de algo que já está feito; e o cubismo, através do re-arranjo e re-montagem de algo que era conhecido anteriormente. Ambos os processos estão diretamente ligados ao conteúdo da letra e àquilo que ela tenta expressar. De acordo com Argan (1992, p. 358): "o ready made apresenta-se como dotado de valor algo a que geralmente não se atribui valor algum”. Assim é com as mulheres do Mangue, a quem a sociedade não atribui nenhum valor e que só possuem atributos estéticos, só podem ter seus pensamentos e sentimentos reconhecidos e considerados porque foram deslocadas da zona para o palco do teatro. $\mathrm{O}$ arranjo cubista que Wisnik faz dos versos de Oswald também é carregado de significado: através dele só vemos os ângulos típicos que fazem com que elas sejam identificadas como prostitutas, todo o restante de sua dimensão humana é ignorado. Não por acaso a parte em que os nomes das mulheres aparecem é habilmente retirada por Wisnik. É interessante notar aqui que Les demoiselles D’Avignon, de 1907 (Disponível em: https://www.moma.org/collection/works/79766), de Pablo Picasso, quadro considerado marco inicial do cubismo, retrata um grupo de prostitutas (Avignon era uma rua famosa por seus prostíbulos) com forte influência estética de elementos africanos. Podemos dizer que, de certa forma, Picasso também construiu uma representação do Mangue. 


\section{O MANGUE RESILIENTE (À GUISA DE CONCLUSÃO)}

Diante de todas as dificuldades impostas à sobrevivência do Mangue e à necessidade da existência deste para atender as demandas da burguesia, cabe a pergunta: por que as classes dominantes pedem o fim da zona? É certo que a hipocrisia católica da moral dos bons costumes faz com que as classes dominantes virem o nariz para a zona por esta ser um símbolo da promiscuidade, mas os mais afetados pelas péssimas condições do Mangue são aqueles que desejam que aquele lugar continue a existir, uma vez que são pessoas sem outras opções de abrigo ou trabalho. O fim do Mangue é também o fim da única estabilidade (por pior que ela seja) na vida daquelas mulheres. Por que, então, cabe aos poderosos, distantes daquele local, cuja vida não é em nada perturbada por aquelas mulheres miseráveis, decidir pelo fim do Mangue?

É que o Mangue, aquela lama em que as mulheres se atolam, aquele lugar de condenados onde as piores crueldades são parte do cotidiano, é também um espaço de resistência que desafia as estruturas do poder estabelecido. Com suas mulheres famintas, estigmatizadas, socialmente relegadas ao nível do esgoto, a própria existência do Mangue é uma afronta à ordem. O Mangue precisa da "carnavalização" (BAKHTIN, 2010) para existir, seu espaço só pode ser espaço também da inversão, uma vez que o indesejado (os homens e seus maus-tratos, suas doenças, mas também seu dinheiro) é aquilo de que aquelas mulheres dependem para subsistir.

O poema de Oswald de Andrade em seu sociocentrismo aponta para a tomada de consciência de classe e para a união dos trabalhadores como forma de acabar com a exploração e a degradação da zona. Oswald teve a intenção de denunciar veementemente as condições de vida da zona e colocar, em "O Santeiro", o debate sobre a existência da prostituição decorrente da pobreza e suas consequências para a sociedade. Para isso o autor recorre a diversas vozes, confrontando diferentes visões sobre um problema específico. Na visão do poeta, o fim do Mangue é necessário por ser sinônimo do fim da exploração.

O teatro mantém o debate oswaldiano, mas agrega um segundo tema para reflexão: o fato de que a simples existência das prostitutas e da zona, com todos os problemas enfrentados por elas, é uma forma de resistência diante da ordem 
estabelecida e, por isso mesmo, os poderosos querem que o Mangue tenha fim. Cabe a Olavo, ainda no meio da peça, a fala final de "O Santeiro", composta a partir dos versos de "Anda depressa, Timochenko". Durante esta fala, o telão projeta diversos grupos da atualidade que são oprimidos e indesejados pelos interesses do capital e cuja existência é, de alguma forma, desafiadora ao poder estabelecido: indígenas, protestos em Brasília, refugiados sírios, africanos, manifestações populares em confronto com a polícia. A fala é coordenada para que as imagens apareçam enquanto Olavo lembra algumas das diferentes instâncias reguladoras de poder social: o direito canônico, a política, os evangélicos, o sentimento da família, as senhoras católicas, etc. Mais adiante, no cassino de Byron, assistimos a Madame Dilma Bovary apostar sozinha contra os homens que formam a BBB (bancada Bíblia-Bala-Boi). O teatro une, através da personagem Dilma-Bovary, duas personagens femininas, uma fictícia e outra real, uma antiga e outra recente, que abertamente desafiaram o poder hegemônico masculino, cada uma a seu modo. No final ambas pagam caro por suas atitudes (não tão caro quanto as mulheres do Mangue).

Não é fruto do acaso a opção da montagem cênica em mostrar a ressurreição de Olavo e Eduléia. A existência dos Olavos, das Eduléias e Deolindas do Mangue é desagradável e difícil de ver. O simples ato de mostrar a realidade da vida daquelas pessoas já pode ser considerado uma forma de agressão à plateia, mas a peça de teatro lembra que ninguém tem o direito de advogar pelo fim do espaço ou da vida de outras pessoas. O casal protagonista, no final da peça, termina na mesma situação em que começou; quase nada mudou com o fim do Mangue. Isso traz um profundo pessimismo ao espectador, mas aceitar a existência daquelas pessoas e da forma que elas escolhem viver, por mais que discordemos de suas opções, é um necessário exercício de empatia e aceitação da alteridade que o teatro põe diante do público.

\section{Referências}

ANDRADE, Oswald de. O santeiro do mangue e outros poemas. São Paulo: Globo, 1991.

ANDRADE, Wellington. O rosário da crítica para a meditação dos mistérios. Revista Cult, 2015. Disponível em: https://revistacult.uol.com.br/home/o-rosario-da-criticapara-meditacao-dos-misterios/. Acesso em: 09 abr. 2021. 
ARGAN, G. C. Arte Moderna. São Paulo: Cia. das Letras, 1992.

BAKHTIN, Mikhail. A cultura popular na idade média e no renascimento: o contexto de François Rabelais. São Paulo: Hucitec, 2010.

CORRÊA, José Celso Martinez. Mistérios Gozozos a Moda de Ópera. Blog do Zé Celso, jun. 2012. Disponível em: https://blogdozecelso.wordpress.com/2012/06/29/misterios-gozozos-a-moda-de-opera/. Acesso em: 09 abr. 2021.

DI CAVAlCANTI, Emiliano. Mangue . 1929. Óleo s/ tela. $53.00 \mathrm{~cm}$ x $25.00 \mathrm{~cm}$. Disponível em: https://enciclopedia.itaucultural.org.br/obra2610/mangue. Acesso em: 09 abr. 2021.

DIAS, Cícero. $O$ Sonho da Prostituta. 1930. Aquarela e nanquim s/ papel. $56.50 \mathrm{~cm} \mathrm{x}$ $51.50 \mathrm{~cm}$. Disponível em: 〈http://enciclopedia.itaucultural.org.br/obra2704/o-sonho-daprostituta $>$. Acesso em: 01 abr. 2021.

FÉRAL, Josette. Além dos limites: teoria e prática do teatro. Trad. por J. Guinsburg (et. al.). $1^{\text {a }}$ ed. São Paulo: Perspectiva, 2015.

FERNANDES, Silvia. Teatralidades Contemporâneas. São Paulo: Perspectiva, 2010.

GOMES, Renato Cordeiro. Plural de vozes na festa (?) do Mangue: uma leitura de $O$ Santeiro do Mangue, de Oswald de Andrade (Dissertação de mestrado). Rio de Janeiro: PUC, Departamento de Letras, 1985.

MAGALHÃES, Fábio. Poéticas do Mangue. Museu Lasar Segall, 2012. Disponível em: http://www.mls.gov.br/exposicoes/temporarias/mls_403/. Acesso em: 01 abr. 2021.

MUNCH, Edvard. Puberdade. 1894. Óleo s/ tela. $151.5 \mathrm{~cm} \times 110 \mathrm{~cm}$. Disponível em: http://www.edvard-munch.org/puberty/>. Acesso em: 09 abr. 2021.

Oficina Uzyna Uzona. Mistérios Gozozos: Versão Oficina Uzyna Uzona 1994. Blog do Zé Celso, 2012. Disponível em: https://blogdozecelso.wordpress.com/2012/06/29/misterios-gozozos -a- moda-de-opera/. Acesso em: 09 abr. 2021.

‥ Mistérios Gozozos - TRANSMISSÃO AO VIVO 27 Novembro - Teatro Oficina. Youtube, 2015. Disponível em: https://www.youtube.com/watch?v=_1LxWu1KPKM\&t=13012s . Acesso em: 09 abr. 2021.

PICASSO, Pablo. Les demoiselles d'Avignon.1907. Óleo s/tela. $243.9 \mathrm{~cm} \times 233.7 \mathrm{~cm}$. Disponível em: https://www.moma.org/collection/works/79766. Acesso em: 09 abr. 2021. 
SEGALL, Lasar. Casa do Mangue. 1929. Xilogravura. $31.50 \mathrm{~cm}$ x $42.00 \mathrm{~cm}$. Disponível em: http://enciclopedia.itaucultural.org.br/obra34480/casa-do-mangue. Acesso em: 09 abr. 2021.

Cabeça atrás da persiana. 1944. Guache s/papel. $37,6 \mathrm{~cm}$ x $30,8 \mathrm{~cm}$. Disponível em: https://artsandculture.google.com/asset/cabe\%C3\%A7a-atras-dapersiana/-QEzBWEuK1klTQ?hl=pt-BR. Acesso em: 09 abr. 2021.

Casal do Mangue. 1929. Xilogravura. $18.00 \mathrm{~cm}$ x $24.00 \mathrm{~cm}$. Disponível em: https://artsandculture.google.com/asset/casal-do-mangue-lasarsegall/cQHKQfwc3acfbw?hl=pt-BR. Acesso em: 09 abr. 2021.

Casal no Mangue. 1943. Xilogravura. $17.00 \mathrm{~cm}$ x $10.00 \mathrm{~cm}$. Disponível em: https://www.moma.org/collection/works/19511. Acesso em: 09 abr. 2021.

SCHWARTZ, Jorge. Fervor das Vanguardas: arte e literatura na América Latina. São Paulo: Cia. das Letras, 2013.

Recebido em: 14/04/2021

Aceito em: 05/07/2021 